\title{
Kelengkapan Imunisasi Dasar Anak Balita dan Faktor-Faktor yang Berhubungan di Poliklinik Anak Beberapa Rumah Sakit di Jakarta dan Sekitarnya pada Bulan Maret 2008
}

\author{
Mathilda Albertina, Sari Febriana, Wibisono Firmanda, Yusie Permata, Hartono Gunardi \\ Departemen Ilmu Kesehatan Anak Fakultas Kedokteran Universitas Indonesia RS Dr. Cipto Mangunkusumo, \\ Jakarta
}

\begin{abstract}
Latar belakang. Program pengembangan imunisasi sudah berjalan sejak tahun 1974. Namun menurut survei kesehatan nasional 2003, cakupan imunisasi lengkap hanya 51\% pada laki-laki dan 52\% pada perempuan.

Tujuan. Mengetahui kelengkapan imunisasi dasar anak balita, alasan ketidaklengkapan imunisasi, serta hubungan pendidikan orangtua, pendapatan keluarga, pengetahuan, dan sikap orangtua dengan kelengkapan imunisasi di beberapa rumah sakit di Jakarta dan sekitarnya.

Metode. Penelitian potong lintang menggunakan kuesioner dengan subjek orangtua dari anak usia 1-5 tahun yang berkunjung ke poliklinik anak RS. Dr. Cipto Mangunkusumo, RS. Fatmawati, RS. Tarakan, dan RS. Mary Cileungsi Hijau Bogor.

Hasil. Didapatkan kelengkapan imunisasi dasar 61\%. Ketidaklengkapan imunisasi umumnya disebabkan orangtua tidak tahu jadwal imunisasi $(34,8 \%)$ dan anak sakit $(28,43 \%)$. Terdapat hubungan antara pengetahuan orangtua dengan kelengkapan imunisasi. Tidak terdapat hubungan antara pendidikan orangtua, pendapatan keluarga, serta sikap orangtua dengan kelengkapan imunisasi.

Kesimpulan. Kelengkapan imunisasi dasar anak balita di tempat penelitian $61 \%$. Faktor yang berhubungan dengan kelengkapan imunisasi ialah pengetahuan orangtua. (Sari Pediatri 2009;11(1):1-7).
\end{abstract}

Kata kunci: imunisasi dasar, anak balita

Alamat korespondensi

DR. Dr. Hartono Gunardi, Sp.A(K). Divisi Tumbuh Kembang Pediatri Sosial. Departemen Ilmu Kesehatan Anak FKUI-RSCM. Jl. Salemba no. 6, Jakarta 10430. Telepon: 021-3160622. Fax.021-3913982
I

munisasi merupakan upaya pencegahan primer yang efektif untuk mencegah terjangkitnya penyakit infeksi yang dapat dicegah dengan imunisasi. ${ }^{1}$ Program Pengembangan Imunisasi (PPI) telah dicanangkan oleh WHO sejak tahun 1974 dengan tujuh penyakit target yaitu difteri, tetanus, 
pertusis, polio, campak, tuberkulosis, dan hepatitis B. Indonesia telah melaksanakan PPI sejak tahun $1977 .^{2}$

Angka cakupan imunisasi masing-masing vaksin PPI pada tahun 2003 cukup tinggi yaitu BCG 97, 9\%, DTP1 96,6\%, Polio3 91,8\%, Campak 89,2\%, dan Hepatitis B3 79,4\%. ${ }^{3}$ Namun menurut hasil survei kesehatan nasional pada tahun 2003, cakupan imunisasi lengkap hanya mencapai $51 \%$ pada laki-laki dan $52 \%$ pada perempuan. ${ }^{4}$

Tujuan penelitian ini adalah mengetahui kelengkapan imunisasi dasar pada anak balita, alasan ketidaklengkapan imunisasi dasar pada anak balita, serta mengetahui apakah terdapat hubungan antara pendidikan orangtua (ayah dan ibu), pendapatan per kapita keluarga, pengetahuan, serta sikap orangtua terhadap imunisasi dengan kelengkapan imunisasi dasar pada anak balita di beberapa rumah sakit di Jakarta dan sekitarnya.

\section{Metode}

Penelitian potong-lintang dilakukan dengan menggunakan kuesioner di poliklinik anak RS. Dr. Cipto Mangunkusumo, RS. Fatmawati, RS. Tarakan, dan RS. Mary Cileungsi Bogor pada tanggal 04-16 Maret 2008. Sampel dihitung berdasarkan rumus survei variabel tunggal, dengan $p=51 \%$ sesuai cakupan imunisasi lengkap menurut survei kesehatan nasional tahun 2003. ${ }^{4}$ Sampel diambil secara consecutive sampling, kriteria inklusi yaitu orangtua memiliki anak balita, ada catatan imunisasi (KMS/kartu imunisasi/ kartu kesehatan lainnya) atau masih ingat mengenai data imunisasi anak. Kriteria eksklusif adalah anak yang menderita penyakit/keadaan sehingga tidak dapat diimunisasi seperti keganasan, HIV/AIDS, dan orangtua menolak berpartisipasi.

Variabel terikat yang diteliti ialah kelengkapan imunisasi dasar anak balita serta alasan ketidaklengkapan imunisasi dasar. Variabel bebas seperti pendidikan orangtua (ayah dan ibu), pendapatan per kapita keluarga per bulan, pengetahuan, serta sikap orangtua terhadap imunisasi. Imunisasi dasar secara lengkap meliputi imunisasi hepatitis B 3 kali, imunisasi polio minimal 3 kali (polio-0 tidak dihitung), BCG 1 kali, DTP 3 kali, dan campak 1 kali. ${ }^{5}$ Pendidikan orangtua diklasifikasikan menjadi rendah (lulus SLTP/sederajat atau kurang), menengah (lulus SLTA/ sederajat), tinggi (lulus perguruan tinggi/akademi). Pendapatan keluarga diklasifikasikan berdasarkan kriteria Bank Dunia $2007^{6}$ setelah dikonversi dengan kurs yang berlaku saat dilakukan penelitian. ${ }^{7}$ Pengetahuan dan sikap orangtua akan diklasifikasikan berdasarkan total skor dari jawaban kuesioner. Pengetahuan dan sikap baik jika $>80 \%$, cukup 60 $80 \%$, dan rendah $<60 \%$ nilai maksimal.

Data dianalisis menggunakan uji chi-square atau Fisher-exact test, menggunakan program komputer SPSS versi 12 . Hubungan antar variabel dianggap bermakna jika dalam uji statistik didapatkan nilai $p$ kurang dari 0,05.

\section{Hasil}

Dalam periode penelitian terkumpul 76 responden dari RS Dr. Cipto Mangunkusumo, 76 responden dari RS. Fatmawati, 76 responden dari RS. Tarakan, dan 86 responden dari RS. Mary Cileungsi. Tabel 1 menunjukkan karakteristik responden di empat tempat penelitian. Sebagian besar responden (32,7\%) memiliki anak berusia 24-35 bulan. Sebagian besar ibu dan ayah berpendidikan menengah yaitu $58,4 \%$ dan $53,7 \%$. Pendapatan per kapita terbanyak adalah pendapatan rendah $(85,5 \%)$, dan tidak ada yang berpendapatan tinggi.

Pengetahuan orangtua sebagian besar tergolong baik $(86 \%)$, hampir semua sikap orangtua tergolong baik (96,2\%) (Tabel 2).

Anak balita yang telah mendapat imunisasi dasar lengkap 61\% dan 39\% lainnya tidak lengkap. Ketidaklengkapan imunisasi paling banyak karena orangtua tidak tahu jadwal imunisasi $(34,8 \%)$ dan anak yang sakit saat hendak diimunisasi $(28,4 \%)$ (Tabel 3).

Analisis hubungan antara pendidikan ayah, pendidikan ibu, pendapatan orangtua, pengetahuan serta sikap orangtua dengan kelengkapan imunisasi didapatkan, hanya pengetahuan orangtua yang memiliki hubungan bermakna dengan kelengkapan imunisasi dasar. Dari faktor yang bermakna, dicari nilai rasio prevalensi dan didapatkan nilai 1,8 yang berarti kelompok responden dengan pengetahuan tinggi memiliki prevalensi kelengkapan imunisasi dasar 1,8 kali lebih besar dibandingkan dengan kelompok dengan pengetahuan sedang serta rendah. 
Tabel 1. Karakteristik sosiodemografi responden

\begin{tabular}{llcc}
\hline Karakteristik & & Frekuensi & $\%$ \\
\hline \multirow{4}{*}{ Usia anak } & $12-23$ & 79 & 25,1 \\
(bulan) & $>23-35$ & 103 & 32,7 \\
& $>35-47$ & 75 & 23,8 \\
Pendidikan & $>47-60$ & 58 & 18,4 \\
ayah & Rendah & 58 & 18,4 \\
& Menengah & 184 & 58,4 \\
Pendidikan & Tinggi & 73 & 23,2 \\
ibu & Rendah & 83 & 26,3 \\
& Menengah & 169 & 53,7 \\
Pendapatan & Tinggi & 63 & 20 \\
per kapita & Rendah & 269 & 85,4 \\
& Menengah papan bawah & 45 & 14,3 \\
& Menengah papan atas & 1 & 0,3 \\
\hline
\end{tabular}

Tabel 2. Pengetahuan dan sikap orangtua terhadap imunisasi

\begin{tabular}{lcccccc}
\hline \multirow{2}{*}{ Orangtua } & \multicolumn{2}{c}{ Kurang } & \multicolumn{2}{c}{ Cukup } & \multicolumn{2}{c}{ Baik } \\
\cline { 2 - 7 } & $\mathrm{n}$ & $\%$ & $\mathrm{n}$ & $\%$ & $\mathrm{n}$ & $\%$ \\
\hline Pengetahuan & 3 & 1 & 41 & 13 & 271 & 86 \\
Sikap & 1 & 0,3 & 11 & 3,5 & 301 & 96,2 \\
\hline
\end{tabular}

Tabel 3. Kelengkapan imunisasi dasar anak balita serta ketidaklengkapan imunisasi

\begin{tabular}{lcc}
\hline \multicolumn{1}{c}{ Kelengkapan imunisasi } & Frekuensi & $\%$ \\
\hline Lengkap & 192 & 61 \\
Tidak lengkap & 123 & 39 \\
$\quad$ Lupa & 24 & 11,76 \\
Sakit & 58 & 28,43 \\
Tidak tahu jadwal imunisasi & 71 & 34,80 \\
Vaksin habis & 2 & 0,98 \\
Tidak ada PIN & 1 & 0,49 \\
Takut efek samping & 48 & 23,53 \\
\hline
\end{tabular}

Keterangan: satu responden dapat memiliki lebih dari 1 alasan

\section{Diskusi}

Penelitian kami mendapatkan angka kelengkapan imunisasi dasar 61\%, sedangkan 39\% lainnya tidak lengkap. Alasan ketidaklengkapan terbanyak ialah ketidaktahuan akan jadwal imunisasi (34,8\%). Sebaiknya Dinas Kesehatan, Puskesmas, Posyandu maupun tenaga kesehatan mempublikasikan mengenai jadwal imunisasi secara lebih luas kepada para orangtua sehingga tidak ada lagi anak yang tidak mendapatkan imunisasi hanya karena orangtua tidak tahu jadwal. Alasan ketidaklengkapan lain yang banyak didapatkan ialah anak sakit saat hendak diimunisasi $(28,4 \%)$ dan orangtua takut akan efek samping imunisasi $(23,5 \%)$. Anak yang sedang sakit memang menjadi kontraindikasi untuk imunisasi tetapi tidak bisa dijadikan alasan ketidaklengkapan karena imunisasi dapat dilakukan bila anak tersebut telah sembuh dari sakit. Efek samping seperti demam atau anak rewel tidak seharusnya menjadi alasan karena ringan dan dapat diatasi. Untuk itu, tenaga kesehatan disarankan untuk memberikan penjelasan mengenai efek samping imunisasi yang dapat terjadi, serta apa yang harus dilakukan orangtua jika terjadi efek samping. Masyarakat juga perlu diberi penjelasan mengenai catch-up immunization sehingga anak-anak yang sakit bisa tetap mendapatkan imunisasi.

Lima variabel yang diteliti berkaitan dengan kelengkapan imunisasi yaitu pendidikan ayah, pendidikan ibu, pendapatan per kapita keluarga per bulan, serta pengetahuan dan sikap terhadap imunisasi. Secara statistik, tidak terdapat hubungan antara pendidikan orangtua dengan kelengkapan imunisasi dasar. Anak balita dengan ayah yang berpendidikan sedang justru memiliki kelengkapan imunisasi dasar yang lebih tinggi daripada anak dengan ayah berpendidikan tinggi, begitu juga dengan variabel pendidikan ibu. Hasil ini sesuai dengan penelitian analisis faktor risiko ketidaklengkapan imunisasi di Kecamatan Tirtomoyo, Kabupaten Wonogiri, yang juga tidak mendapatkan hubungan antara pendidikan orangtua dengan kelengkapan imunisasi. ${ }^{8}$ Namun, hasil yang berbeda ditunjukkan pada penelitian yang dilakukan di Kabupaten Aceh Besar tahun 19981999. ' Pada penelitian tersebut didapatkan adanya hubungan antara tingkat pendidikan ibu dengan kelengkapan imunisasi. Selain itu penelitian M. Ali $2002^{10}$ menyatakan bahwa pendidikan sebenarnya sangat penting dalam mempengaruhi pengertian dan partisipasi orang tua dalam program imunisasi. Dengan pendidikan yang semakin tinggi, maka orangtua cenderung menggunakan sarana kesehatan sebagai suatu upaya pencegahan bukan pengobatan. Perbedaan tersebut dapat disebabkan oleh penyebaran sampel yang tidak merata pada tiap kelompok. Selain itu, tidak adanya hubungan pendidikan dengan kelengkapan imunisasi dapat disebabkan 
karena informasi tentang imunisasi lebih banyak didapat melalui media masa, bukan dari sekolah atau pendidikan formal.

Pendapatan per kapita juga tidak mempunyai hubungan dengan kelengkapan imunisasi dasar. Pada kelompok orangtua dengan pendapatan per kapita rendah, angka kelengkapan lebih tinggi dibandingkan kelompok lain. Hal ini disebabkan karena hampir semua anak pada penelitian ini mendapatkan imunisasi di Puskesmas/Posyandu secara gratis, hanya perlu membayar biaya administrasi yang relatif murah. ${ }^{11} \mathrm{Hal}$ ini sesuai dengan penelitian Ahmad Rois mengenai analisis faktor risiko ketidaklengkapan imunisasi bayi di Kecamatan Tirtomoyo Kabupaten Wonogiri. ${ }^{8}$

Pengetahuan orang tua merupakan satu-satunya variabel yang memiliki hubungan bermakna dengan kelengkapan imunisasi dasar. Kelompok orangtua dengan pengetahuan yang baik menunjukkan angka kelengkapan imunisasi dasar yang lebih tinggi daripada kelompok lainnya. Hasil ini sesuai dengan penelitian di Puskesmas Lanjas Kabupaten Barito Utara, yang mendapatkan bahwa pengetahuan ibu memiliki hubungan yang bermakna dengan kelengkapan imunisasi. ${ }^{12}$ Namun, berbeda dengan penelitian Masjkuri tentang pengetahuan orang tua tentang imunisasi di Kebayoran Lama, Jakarta Selatan dan penelitian Suharsono tentang pengetahuan, sikap, dan perilaku ibu-ibu etnis Tionghoa tentang imunisasi di Kecamatan Kelapa Kampit, Kabupaten Belitung, yang tidak mendapatkan hubungan antara pengetahuan orangtua dengan status imunisasi anak. ${ }^{10}$ Pengetahuan ikut berperan dalam mengambil berbagai keputusan. Pengetahuan masyarakat yang minim mengenai imunisasi dapat menyebabkan keikutsertaan dalam program imunisasi juga minim.

Tidak didapatkan hubungan antara sikap orangtua terhadap imunisasi dengan kelengkapan imunisasi. Berbeda dengan penelitian yang pernah dilakukan mengenai faktor-faktor yang mempengaruhi kelengkapan imunisasi hepatitis B pada bayi di wilayah Puskesmas Banyu Urip Kodamadya Surabaya pada tahun 1994. Penelitian tersebut menyatakan bahwa sikap ibu-ibu terhadap imunisasi hepatitis B berpengaruh terhadap kelengkapan imunisasi hepatitis B. ${ }^{13}$ Tidak adanya hubungan antara sikap orangtua dengan kelengkapan imunisasi dapat disebabkan karena tidak meratanya jumlah responden pada tiaptiap kelompok.

\section{Kesimpulan}

Didapatkan 61\% anak balita memiliki status imunisasi dasar yang lengkap dan 39\% lainnya tidak lengkap. Hampir semua responden memiliki pengetahuan (86\%) dan sikap $(96,2 \%)$ yang baik terhadap imunisasi. Adapun alasan ketidaklengkapan imunisasi dasar terbanyak ialah orangtua tidak tahu jadwal imunisasi $(34,8 \%)$. Terdapat hubungan yang bermakna antara pengetahuan orangtua mengenai imunisasi dengan kelengkapan imunisasi dasar dasar anak balita di poliklinik anak beberapa rumah sakit di Jakarta dan sekitarnya.

\section{Ucapan terima kasih}

Ucapan terimakasih kepada pimpinan beserta staff RS Dr. Cipto Mangunkusumo, RS. Tarakan, RS. Fatmawati, dan RS. Mary Cileungsi atas izin yang diberikan untuk melaksanakan penelitian ini. Semoga hasil penelitian ini berguna bagi perkembangan kesehatan anak di Indonesia.

\section{Daftar pustaka}

1. Achmadi UF. Imunisasi: mengapa perlu? Jakarta: Penerbit buku Kompas; 2006.h.130.

2. WHO. Expanded program on immunization overview. Diunduh dari: http://wbln0018.worldbank.org/HDNet/ HDdocs.nsf_pada_1 Desember 2007.

3. Departemen Kesehatan RI. Profil kesehatan indonesia 2003. Jakarta: Departemen Kesehatan RI; 2005.h.165.

4. Badan Penelitian dan Pengembangan Kesehatan Departemen Kesehatan RI. Status kesehatan masyarakat berbasis gender: fakta dari hasil survei kesehatan nasional. Jakarta: Depkes RI; 2006.h.27.

5. Jadwal imunisasi 2007 rekomendasi Ikatan Dokter Anak Indonesia (IDAI) periode 2007.

6. World Bank. Country Classification. Diunduh dari: http://go.worldbank.org/K2CKM78CC0 pada 19 Maret 2009.

7. Bank Indonesia. Kurs uang kertas Indonesia tanggal 28 Februari 2008. Diunduh dari: www.bi.go.id/biweb/templates/ moneter pada 22 Mei 2009.

8. Rois A. Analisis faktor risiko ketidaklengkapan imunisasi bayi di Kecamatan Tirtomojo Kabupaten Wonogiri. Diunduh dari: http://digilib.unikom.ac.id/go.php?id=jkpkbppkgdl-res-2000-achmad-637-imunisasi pada 16 April 2008 
9. Idwar. Faktor-faktor yang berhubungan dengan status imunisasi hepatitis B pada bayi (0-11 bulan) di Kabupaten Aceh Besar Propinsi Daerah Istimewa Aceh tahun 1998-1999. Diunduh dari: http://digilib.litbang. depkes.go.id/go.php?id=jkpkbppk-gdl-res-2000-idwar2181-acehor $q$ =sikap tanggal 22 April 2008.

10. Ali M. Pengetahuan, sikap, dan perilaku ibu bekerja dan ibu tidak bekerja tentang imunisasi. Diunduh dari http:/llibrary. usu.ac.id/download/fklanak-muhammad.pdf pada 22 April 2008.

11. Anwar C. Perencanaan kesehatan berbasis fakta $\&$ belajar dari KLB polio. Diunduh dari: http://fpks-dpr.or.id/new/ main.php?op=isiorid=1167 (20 Desember 2007).
12. Siswandoyo. Faktor-faktor yang berhubungan dengan status kelengkapan imunisasi hepatitis B pada bayi di Puskesmas Lanjas Kabupaten Barito Utara. Diunduh dari: http://digilib.litbang.depkes.go.id/go.php?id=jkpkbppk-gdlres-2002siswandoyo-2198-imunisasi\& $q=$ faktor-faktor $+y$ an g+berhubungan+dengan+imunisasi.

13. Soekeksi, Indra N. Faktor-faktor yang mempengaruhi kelengkapan imunisasi hepatitis b pada bayi di wilayah puskesmas banyu urip kodamadya surabaya tahun 1994. Diunduh dari: http://digilib.litbang.depkes. go.id/go.php?id=jkpkbppk-gdl-res-1995-soekeksi2c-2199puskesmase $q=$ mempengarubi pada 15 Februari 2008. 


\section{Lampiran:}

\section{Kuesioner \\ Data responden}

Nama responden (orangtua) :

Nama anak

Usia

Alamat lengkap

No. Telp/HP

Pekerjaan

ayah

ibu

Pendidikan terakhir

ayah :

Penghasilan total keluarga :

Jumlah tanggungan keluarga :

1. Apakah anda mengetahui tentang imunisasi?

a. Ya

b. Tidak

2. Apakah anda mengetahui tentang tujuan imunisasi?
a. Ya
b. Tidak

\section{Pengetahuan}

3. Menurut Anda, apakah yang dimaksud dengan imunisasi?
a. Upaya pencegahan terhadap penyakit infeksi
b. Upaya pengobatan terhadap penyakit infeksi
c. Upaya meningkatkan berat badan anak
d. Upaya peningkatan gizi anak
e. Tidak tahu

4. Penyakit apa yang bisa dicegah dengan imunisasi?
a. Diare
b. Demam Berdarah
c. Campak
d. Infeksi telinga
e. Tidak tahu

5. Apa manfaat imunisasi?
a. Supaya anak tidak terjangkit penyakit infeksi
b. Untuk meningkatkan kepintaran anak
c. Agar anak tidak rewel
d. Agar nafsu makan anak bertambah
e. Tidak tahu

6. Berikut ini yang termasuk cara pemberian imunisasi?
a. Diteteskan ke mata
b. Diteteskan ke telinga
c. Disuntikan di betis
d. Disuntikan di paha
e. Tidak tahu

7. Kapan seharusnya anak anda pertama kali diimunisasi?
a. Usia sekolah
b. Usia 2 tahun
c. Usia 1 tahun
d. Sejak lahir
e. Tidak tahu

8. Kapan imunisasi pada anak harus ditunda?
a. Anak sedang demam tinggi
b. Anak masih mengkonsumsi ASI
c. Anak sehat
d. Anak banyak makan
e. Tidak tahu

9. Bagaimana cara kerja imunisasi?
a. Meningkatkan daya tahan tubuh
b. Meningkatkan nafsu makan
c. Menyembuhkan penyakit
d. Membunuh kuman penyakit
e. Tidak tahu

10. Apakah yang diberikan saat imunisasi?
a. Kuman yang dilemahkan
b. Vitamin
c. Antibiotik
d. Obat
e. Tidak tahu

11. Imunisasi apakah yang pemberiannya diteteskan ke mulut?
a. Hepatitis B
b. BCG
c. Polio
d. DPT
e. Tidak tahu

\section{Sikap}

12. Apakah Anda setuju jika anak anda diimunisasi?
a. Ya
b. Tidak
c. Ragu-ragu

13. Apakah Anda setuju bahwa imunisasi itu penting untuk kesehatan anak?
a. Ya
b. Tidak
c. Ragu-ragu 
14. Apakah Anda setuju bahwa manfaat yang didapat dari imunisasi lebih besar daripada kerugiannya (efek samping)?
a. Ya
b. Tidak
c. Ragu-ragu

15. Jika Anda mendengar laporan mengenai efek samping yang terjadi setelah imunisasi dari orang lain, apakah Anda masih memberikan anak anda diimunisasi?
a. Ya
b. Tidak
c. Ragu-ragu

16. Jika anak anda mengalami demam setelah imunisasi, apakah Anda masih akan memberikan imunisasi selanjutnya kepada anak anda?
a. Ya
b. Tidak
c. Ragu-ragu

17. Jika pelayanan kesehatan yang menyediakan layanan imunisasi (RS/puskesmas/posyandu/ praktek dokter) jauh dari rumah Anda, apakah Anda mau mengantarkan anak anda diimunisasi?
a. Ya
b. Tidak
c. Ragu-ragu

18. Jika biaya imunisasi memberatkan Anda, apakah Anda akan tetap mengimunisasi anak anda?
a. Ya
b. Tidak
c. Ragu-ragu

\section{Kelengkapan Imunisasi}

19. Apakah anak anda pernah diimunisasi?

Jika pernah, silakan lanjutkan ke nomor berikutnya. Jika tidak pernah, mengapa?
a. Tidak tahu jadwal imunisasi
b. Jarak rumah ke posyandu/puskesmas/klinik/ rumah bersalin/RS jauh
c. Mahal
d. Takut dengan efek samping (takut anak sakit)
e. Lain-lain:

20. Apakah anak anda telah diimunisasi hepatitis B?
a. Sudah
Berapa kali? kali
b. Belum
i. Tidak tahu jadwal imunisasi

Mengapa?
ii. Lupa
iii. Rumah jauh
iv. Mahal
v. Takut dengan efek samping
vi. Lain-lain:

21. Apakah anak anda telah diimunisasi BCG?

a. Sudah

Berapa kali? kali

b. Belum

Mengapa?

i. Tidak tahu jadwal imunisasi

ii. Lupa

iii. Rumah jauh

iv. Mahal

v. Takut dengan efek samping

vi. Lain-lain:

22. Apakah anak anda telah diimunisasi Polio?
a. Sudah
Berapa kali? kali
b. Belum
Mengapa?
i. Tidak tahu jadwal imunisasi
ii. Lupa
iii. Rumah jauh
iv. Mahal
v. Takut dengan efek samping
vi. Lain-lain:

23. Apakah anak anda telah diimunisasi DTP?
a. Sudah
Berapa kali? kali
b. Belum
Mengapa?
i. Tidak tahu jadwal imunisasi
ii. Lupa
iii. Rumah jauh
iv. Mahal
v. Takut dengan efek samping
vi. Lain-lain:

24. Apakah anak anda telah diimunisasi campak?
a. Sudah
Berapa kali? kali
b. Belum

Mengapa?

i. Tidak tahu jadwal imunisasi

ii. Lupa

iii. Rumah jauh

iv. Mahal

v. Takut dengan efek samping

vi. Lain-lain: 